\title{
Aliaga Méndez, JUAN ANTONio (2010). Normativa comentada de prevención del blanqueo de capitales. Adaptada a la Ley 10/2010, La Ley: Madrid, 859 pp.
}

Durante las últimas décadas se ha comprendido que el fenómeno del lavado de activos o blanqueo de capitales ha de ser afrontado no solo por medio de la tipificación y posterior sanción penal de las conductas constitutivas del mismo, sino que además a través del diseño e implementación de las denominadas medidas de prevención. Este segundo enfoque consiste en la formulación de ciertos deberes que han de satisfacer distintos agentes del sistema económico y financiero, tales como bancos, casas de cambio, bolsas de valores, casinos, notarios, conservadores, empresas de leasing, empresas de transferencia de dinero, agentes de aduanas, entre otros. Ello con el encomiable propósito de impedir que los capitales provenientes de actividades ilícitas ingresen a dicho sistema y así lograr el debilitamiento de las organizaciones criminales. Es precisamente esta última perspectiva la que, de forma predominante, se aborda en la obra objeto del presente comentario.

Chile no ha estado ajeno a la implementación de las medidas de prevención del lavado de activos. El marco básico de la actividad jurídica desarrollada en este ámbito se cristaliza en el texto actual de la Ley 19.913, que crea la Unidad de Análisis Financiero (UAF) y modifica diversas disposiciones en materia de lavado y blanqueo de activos ${ }^{1}$. Los sujetos obligados por esta normativa han de cumplir con los deberes básicos que la regulación apuntada establece y que, en su mayoría, han sido desarrollados a través de numerosas circulares de la $\mathrm{UAF}^{2}$.

Conforme al enfoque internacional que ha de observarse a la hora de afrontar la prevención del lavado de activos, el Grupo de Acción Financiera Internacional (GAFI o FATF en sus siglas en inglés) -principal organismo especializado en esta materia- ha establecido determinados estándares mínimos exigibles a los diversos Estados en este ámbito. Estos estándares se reflejan en las conocidas Cuarenta Recomendaciones del GAFI, a las que cabe agregar las Nueve Recomendaciones Especiales contra el Financiamiento del Terrorismo ${ }^{3}$. En este contexto se realizan, de forma periódica, evaluaciones relativas al cumplimiento de las Recomendaciones ${ }^{4}$.

D.O. de 18.12.2003. Modificada por la Ley 20.119 (D.O. de 31.08.2006) y la Ley 20.393 (D.O.02.10.2009).

A este respecto, véase www.uaf.cl (última visita realizada con fecha 27.05.2010).

Estos instrumentos pueden consultarse en www.fatf-gafi.org (última visita realizada con fecha 27.05.2010)

4 En el ámbito sudamericano destaca la labor realizada a este respecto por el Grupo de Acción Financiera de Sudamérica (GAFISUD). Respecto de la actividad de este organismo, véase www.gafisud.info/ (última visita realizada con fecha 27.05.2010). 
Chile fue objeto de examen los años 2003, 2006 y 2010. Como consecuencia de estas evaluaciones, debió -y deberá, en el futuro- desplegarse la actividad legislativa necesaria destinada a satisfacer suficientemente los estándares internacionales de prevención del lavado de activos.

También, como consecuencia de una evaluación del GAFI realizada el año 2006, así como de importantes presiones a nivel comunitario, España cuenta, a partir de abril de 2010, con la Ley 10/2010, de prevención del blanqueo de capitales y de la financiación del terrorismo ${ }^{5}$ (en adelante, la Ley 10/2010). Esta normativa vino a transponer al ordenamiento jurídico español y a completar el régimen establecido en la Directiva 2005/60/CE, de 26 de octubre de 2005, relativa a la prevención de la utilización del sistema financiero para el blanqueo de capitales y para la financiación del terrorismo ${ }^{6}$ (en adelante Directiva 2005/60/CE).

Precisamente es el texto de esta Ley aquel analizado en el libro objeto del presente comentario. Su autor, Juan Antonio Aliaga Méndez, con vasta experiencia en materia de prevención del blanqueo de capitales, ha representado a España en distintos foros sobre la materia, entre los que se cuenta la Comisión Europea y el GAFI. En nuestra opinión, esta circunstancia atrae al lector en busca de un análisis de la nueva normativa de prevención española que tenga especialmente en cuenta los estándares internacionales existentes a este respecto. Así, su contenido no solo resulta de interés para los lectores espańoles, sino para todos quienes estudian la implementación de los estándares del GAFI.

La obra que comentamos contiene un análisis, artículo por artículo, tanto del texto de la Ley 10/2010 como de la normativa reglamentaria aplicable en España ${ }^{7}$ en materia de prevención del lavado de activos. El valor de la sistemática escogida por el autor radica en su sencillez, ya que se seńala, a propósito de cada artículo el tema que este aborda. Así, resulta fácil consultar el texto.

Luego, el libro contempla un completo anexo con documentos de variado tipo, entre los que se destacan diversas directivas comunitarias elaboradas en este ámbito, así como las ya mentadas Recomendaciones del GAFI.

Por último, se valora de forma positiva el hecho que la obra contenga una tabla informativa con aquellos sitios web más importantes sobre temáticas atingentes a la prevención del blanqueo de capitales. Ello sin

BOE N $\mathrm{N}^{\circ} 103$ de 29.4.2010.

DOUE L 309 de 25.11.2005.

Constituida por el Real Decreto 925/1995, de 9 de junio, por el que se aprueba el Reglamento de la Ley 19/1993, de 28 de diciembre, sobre determinadas medidas de prevención del blanqueo de capitales (BOE $\mathrm{N}^{\circ} 160$ de 6.7.1995). De acuerdo con lo que establece la disposición adicional primera de la Ley 10/2010, dicho reglamento que desarrolló el contenido de la antigua ley de prevención del blanqueo de capitales española, permanece en vigor en tanto no entren en vigencia las propias disposiciones reglamentarias de la Ley 10/2010. 
duda permite, a quien se inicia en el estudio de estas materias, acceder fácilmente a su conocimiento.

Al abordar los diversos temas tratados, el autor dedica una sección a anotar las concordancias entre los artículos de la Ley 10/2010, las Recomendaciones del GAFI y la Directiva comunitaria, así como respecto de otros instrumentos internacionales relativos a la prevención del blanqueo de capitales. Ello permite comprender, de modo sencillo, cómo se ha intentado a través de la Ley, dar cumplimiento a los estándares internacionales sobre la materia. A este respecto, el libro contiene, en su parte final, un cuadro con las concordancias entre los distintos instrumentos indicados.

Ahora bien, lo que resulta de mayor interés son los comentarios que el autor realiza respecto de cada uno de los artículos de la Ley 10/2010, así como de la normativa reglamentaria. No se trata de una tarea sencilla, ya que estamos en presencia de una regulación en permanente proceso de adaptación e implementación a los estándares internacionales ${ }^{8}$. A propósito de esta actividad, se dedican varias páginas a temáticas que necesariamente se han de tener en cuenta al momento de ajustar cumplidamente la normativa local a los estándares internacionales elaborados por el GAFI. Así, el autor analiza la doble estrategia diseñada para afrontar el fenómeno del blanqueo de capitales; la finalidad perseguida por la normativa de prevención; el concepto de financiación del terrorismo; la necesaria expansión del catálogo de sujetos obligados y su fundamento; el alcance y relación que han de tener deberes de prevención como el de examen especial de operaciones sospechosas y su comunicación a las autoridades locales; el sentido y antecedentes de la obligación de abstención de ejecución de determinadas operaciones, así como los de la prohibición de revelar a terceros la existencia de sospechas de blanqueo; el alcance de las medidas de control interno, entre muchos otros tópicos.

Sin duda, la mayor innovación en el contexto de la normativa espańola y que en el futuro puede servir de referente para profundizar los avances experimentados a nivel local, es aquella relativa a la medida de prevención denominada "conocimiento de los clientes" o diligencia debida (due diligence) con respecto a los clientes. Esta, según da cuenta el propio autor de la obra, constituye el pilar fundamental sobre el que descansa todo sistema de prevención del blanqueo de capitales. En este punto, la Ley 10/2010, cumpliendo con los requerimientos del GAFI y de la Directiva 2005/60/CE, determina la aplicación de esta medida en función del riesgo de lavado de activos que representa el cliente u operación que se trata. Así, es posible distinguir entre un régimen general de identifica-

\footnotetext{
8 Tal como señala Javier Zaragoza Aguado, Fiscal jefe de la Audiencia Nacional española, en el prólogo de la obra objeto del presente comentario.
} 
ción y otro "reforzado" para aquellos supuestos que representan un riesgo superior al promedio, de acuerdo con los propios criterios establecidos en la Ley. Finalmente, se contemplan medidas de diligencia debida simplificadas para los casos en que el riesgo de blanqueo de capitales sea escaso o limitado.

Respecto de este punto, en el libro objeto del presente comentario se analizan los enfoques diseñados para la regulación e interpretación del deber de conocimiento de los clientes a nivel internacional. Además, se ponen de relieve los estándares que se manejan a este respecto para los distintos sujetos obligados por la normativa de prevención. Especialmente interesantes resultan también los comentarios que el autor realiza respecto del deber de identificar al "titular real", presente usualmente en aquellos casos de empleo instrumental de personas físicas y jurídicas. En este contexto, se da cuenta de las dificultades con que se puede encontrar un sujeto obligado para dar cumplimiento a este deber y se proponen soluciones para abordarlas. También se refiere latamente al denominado "conocimiento del negocio", resaltando su importancia y alcance, así como al deber de seguimiento continuo (monitoreo) de las relaciones de negocio, necesario para detectar operaciones sospechosas una vez que se ha iniciado una relación comercial con un cliente.

Sin que ello reste mérito alguno al libro objeto del presente comentario, en aquello que dice relación con el "régimen general" de conocimiento de los clientes, se echa en falta un análisis más profundo y crítico en torno al concepto mismo de "cliente" a la luz de la normativa de prevención del blanqueo. Ello teniendo en cuenta que este concepto constituye el supuesto básico para la aplicación de dicha normativa. También creemos que sería deseable un análisis más acabado del art. 8 de la Ley 10/2010, que franquea la posibilidad de colaboración entre sujetos obligados para el cumplimiento de las medidas de diligencia debida. La norma establece importantes limitaciones para articular dicha cooperación, tan deseada por los sujetos obligados a fin de ahorrar costos de tiempo y dinero relacionados con el cumplimiento de las medidas en comento. No tenemos dudas que la obra que recensionamos tendrá nuevas ediciones en las que se ahondará sobre estas temáticas, a medida que la propia Ley 10/2010 ande camino y se puedan evidenciar sus vacíos o falencias más importantes.

Por su parte, en cuanto a las "medidas de diligencia debida simplificadas", resulta especialmente atractiva la actividad que realiza el autor de cara a concordar lo dispuesto a este respecto en la Ley 10/2010 con los estándares establecidos en este ámbito por GAFI y la Directiva 2007/60/ CE. Por último, el libro que comentamos recoge también las denomina-

9 Conocido también como "beneficiario final" o beneficial owner. 
das "medidas de diligencia debida reforzadas", aplicables en aquellos casos de riesgo elevado de lavado de activos. El autor se refiere a aquellos deberes especiales que han de ser aplicados a las relaciones de negocio y operaciones no presenciales; a las relaciones de corresponsalía bancaria transfronteriza; a las personas con responsabilidad pública; y a los productos $\mathrm{u}$ operaciones propicias al anonimato y nuevos desarrollos tecnológicos. El tratamiento que se realiza de estos deberes en cuanto a su extensión, resulta proporcionado respecto de las demás secciones de la obra. Sin embargo, de cara a su consulta para la solución de problemas prácticos que pueda suscitar la aplicación de dichas medidas sería recomendable profundizar en el análisis de las mismas. Ello resulta particularmente evidente en el caso de las medidas de prevención del lavado de activos diseñadas para las relaciones de negocio y operaciones no presenciales. Estas se enmarcan en la interesante y actual temática de la relación del blanqueo de capitales y las nuevas tecnologías, que presenta una complejidad propia que vale la pena analizar con mayor detalle.

En conclusión, estamos en presencia de una obra relevante para el estudio de la nueva normativa española de prevención del blanqueo de capitales. Sin embargo, allí no se agota su valor. Además, permite conocer de forma sencilla y concreta tanto la forma de incorporar a un ordenamiento jurídico los estándares internacionales actuales en materia de prevención de lavado de activos, como los problemas con que nos podemos encontrar en este escenario. Desde esta perspectiva, creemos que su contenido ha de ser considerado a la hora de estudiar futuras reformas a la regulación chilena en esta materia.

Angela Toso Milos*

* Doctora en Derecho, profesora de Derecho Comercial de la Universidad Católica del Norte, sede Antofagasta. Correo electrónico: antoso@ucn.cl 